\title{
The training of international librarians
}

\author{
How to host a successful internship
}

by Yvonne de Souza

$\mathrm{E}$ ducation for librarianship in North America involves preparation by means of a formal program of studies at the end of which a degree (such as the MLS) or a diploma (such as that for paraprofessionals) is obtained.

While a professional degree is the required education for a professional position in North America, the cost of obtaining this in North America could be exorbitant for students from other countries. Apart from tuition costs, there are living expenses and airfare to consider. Governments of developing countries may not be able to afford the high costs of a postgraduate degree program and there are very limited sources of funds from aid agencies.

Often library personnel seek further training, having undergone library education in their home country where this education (and not necessarily an MLS) serves as admittance into the profession. The level of English required to undertake an MLS program could be a major deterrent for librarians abroad.

A North American librarian conducting training in another country would be a less expensive model. However, training in North America, no matter how short the program, offers the opportunity to observe how libraries in North America operate and gives insight into the standards in technical and pub- lic services. Libraries can play a role in the education of international librarians.

This article documents the experiences of an internship at Columbia College, an international liberal arts college located in Vancouver, and presents suggestions to libraries that may be interested in hosting international library staff. The trainee was from the Center for Oceans Research Information in Vietnam. The mandate of the information center is to provide information for management decisions in the area of marine-related issues. The project was funded by the Canadian International Development Agency. Tuition, air transport, and a per diem allowance sufficient to pay for accommodations and other living expenses for the trainee were covered by the funding. The training period was three months.

\section{Planning the program}

Limited funding sources coupled with the high costs of training librarians from different countries in North America, make it imperative that the program be thoroughly planned, yet allow for a degree of flexibility and that strategies be put in place to ensure success.

\section{Use of background information}

As most internships are shorter than a formal 
program of study, maximum use of time is crucial. To develop an effective training schedule, the trainer cannot work in a vacuum with regard to the trainee's background. The trainer should have:

- knowledge of the trainee's background, language ability, skills, and knowledge (for example, does the trainee have experience with Windows?),

- knowledge of the type of library or information center that the trainee is from or will be working in upon return,

- a good understanding of the duties that the trainee will be performing, and

- an awareness of the conditions of the trainee's work environment (for example, what telecommunications infrastructure exists? Is there a good Internet connection?).

The trainee should be asked to provide an outline of education, training, and work prior to arrival in North America. This could be in the form of a resume. Details regarding the information center under development and the mandate of the information center can also be provided by the trainee's organization or from an overall project coordinator, if there is one.

\section{English language abilities}

While many international students have English language abilities, the level of this ability may need upgrading. An innovative approach would be to incorporate English language training into the internship. An academic library could work with the English Language Department of the institution to fit the trainee into an appropriate level.

Columbia College Library was fortunate in this regard, as the English Language Center is an extension of the college and its proximity to the library facility was convenient for the trainee. While improvements in language ability over such a short period of time would probably be modest, this improvement in speaking, writing, and reading abilities in English would:

- enhance the acquisition of library-related knowledge,

- improve the absorption of content information (marine resources),

- enable the trainee to adjust better to her new environment, and

- provide substantial opportunity for the trainee to mingle with language students from many other countries and to acquire a measure of confidence in communicating with library and other academic staff as a result of becoming familiar with North American figures of speech.

\section{Choice of training locations}

The choice of an appropriate library venue could offer inherent advantages. Trainers and libraries considering an internship program, may wish to move away from a single venue for training. A combination of carefully chosen library venues can open up the door to a broader training experience, allowing each library involved to concentrate on what it does best.

For example, a trainee wanting to learn how to set up and manage a small information center could spend about two-thirds time in a small library and observe how different areas of the library operate and are interrelated, and the rest of the time in a library with a specialized collection of interest to the trainee. In the case of the internship undertaken by Columbia College, the trainee was from an organization that deals with marinerelated issues. The training took place at two locations:

- two months at the college. (This allowed ample opportunity to interact with the trainer and mentor, work in different aspects of library operations, and observe the adoption of new technologies in smaller libraries and their impact on the delivery of services), and

- one month at a special library whose subject collection (marine resources) was closely related to that of the trainee's work environment. This period allowed the trainee to work with specialized subject resources and to continue practicing the use of applicable software (e.g., Procite) already in place in the trainee's information center.

\section{Customization}

Internship often calls for customization, as trainees may have undergone training in their home country and may wish to focus on one area of library and information work. This particular internship was unique in several respects. The training in Canada was preceded and followed by input and assistance from a Canadian librarian, who was the $\mathrm{CO}^{-}$ ordinator of the information component of a larger project (Vietnam-Canada Oceans 
Project, funded by the Canadian International Development Agency). Working with the executive administrators in Vietnam, gave this librarian the advantage of being able to present a librarian's perspective on the organization and running of the center's library.

\section{Preliminary interview}

Although information about the trainee may have been gathered, a personal interview is recommended, the purpose being to:

- explain the content and nature of the internship;

- inform the trainee of the trainer's expectations (hours of attendance, readings, activity log, and a final short report to include a few specific applications that the trainee would expect to implement on return to the trainee's information center);

- to verify the trainee's objectives /requirements; and

- to find out what particular areas/topics the trainee would like to see added and to ask for feedback after the trainee has had the opportunity to examine the training schedule.

\section{Strategies}

Congenial training environment. During the internship, the trainee should be regarded as a member of the library staff and keep the same hours. The trainee should be given a good amount of work space, preferably a separate computer workstation, stationery, and access to a photocopier. Borrowing privileges and a personal e-mail account should be made available. A supportive and positive learning environment can make a difference to the trainee's experiences.

Content-based learning experiences. In this case, the broad subject area of ocean resources policy and legislation was the subject base around which the various activities revolved. Whether using search engines, creating and arranging bookmarks or creating records for the organization and retrieval of Web sites, in-depth indexing for improved access, the material sought was within the broad scope of the subject areas of the trainee's library marine-related issues.

One particularly relevant exercise was the use of the ASFA (Aquatic Sciences and Fisheries Abstract) thesaurus in indexing marinerelated resources. A content-based framework ties together different activities.
Activity log. Keeping an activity log should be considered. In this instance, it was helpful as it compelled the trainee to write in English. The trainee also compiled readings, notes, and worksheets. The package served not only as a log of what the trainee did, but also as a reference tool for the trainee's future use.

Cataloguing/indexing templates (especially of relevant format types), notes, useful Web sites collected by the trainee, and mail lists addresses were typical items. Keeping a log also helped the trainee to have a sense of accomplishment.

Periodic evaluation. Even thorough planning may not result in a perfect training schedule. However, if periodic evaluation is built into the program, it can provide the opportunity for the trainer to modify sections of the program to accommodate special needs that the trainee may have expressed and thus ensure that the content, focus, and methodology are in line with the objectives.

\section{Tutorials, readings, and assignments}

Apart from practical experience, readings and assignments can enrich the internship. The trainer can choose to have these completed at home. The trainee could be asked to do some research and identify useful articles, providing excellent opportunities to use databases (such as "CARL," "Proquest," or "EbscoHost") within the library or at another library. Having the trainee complete this at home reinforces things learned during the day and helps the trainee focus on the training program and not feel homesick.

Tutorials can take place once a week or once a fortnight and provide the opportunity for the trainee to raise questions, seek clarification, and engage in discussion with the librarian (and mentor) who is overseeing the internship.

\section{Site visits}

Site visits could easily turn into just a visit. If structure is built in, albeit a loose one, it introduces a focus. A site visit could be one where the trainee searches databases that are not available to the host library.

While several types of libraries can be included, one of them should be a library that is similar to the library that the trainee is from. 
It was fortunate in this instance that the $\mathrm{Pa}$ cific Salmon Commission Library could accommodate a visit, as the nature of the collection was of great interest to the trainee.

Trainees can prepare for library tours or visits by obtaining a brief description of the library/information center and the clientele it serves. The preparation can also take the form of encouragement to ask questions and guidance as to the kinds of questions that the trainee can raise and what specific things to observe during the visit.

It was noted that on a site visit late in the training period, the trainee was more vocal and displayed greater confidence in asking questions of the host librarian than on an earlier visit, attesting to the value of the English-language training.

\section{Ease of adjustment}

The trainee should be met upon arrival at the airport and accompanied to the home where he or she will be living. The level of anxiety that the trainee is anticipated to face, having to confront the unfamiliar, should be kept to a minimum. For many, it may be the first time away from home and even the mundane escalator can be a novelty.

Meeting a trainee before the program begins can melt the ice and enable the trainer to obtain some insight into the trainee's personality, likes, dislikes, and special needs. It is a good idea to allow a few days as "free" time to get over jet lag and settle in. Homestays should be selected on the basis of ease of obtaining public transport to and from the training sites and the receptivity of the family to people of diverse ethnic origins.

Information helpful to trainees include places to shop for groceries, awareness of seasonal prices, getting to know the transit system, and becoming familiar with the legal tender. Social graces and etiquette are skills that the trainee may need to acquire quickly.

Assistance beyond library matters is indeed time consuming yet crucial to the success of the program because it eases the anxiety of adjustment to North American life.

\section{Conclusion}

Libraries that are interested in taking on an internship program have to be aware of the time and effort involved before undertaking such a program. ${ }^{1}$ Whether the internship fo- cuses on a special area of library operations or attempts to provide an overview of library operations in North America, or a combination of both, there is no doubt that to ensure success, careful planning and the flexibility of making necessary changes, coupled with a commitment of time beyond regular training hours are key ingredients.

The training period spent in a North American library provides a firsthand look at the standards that libraries in North America adhere to and presents an environment whereby the trainee can reflect on the application of certain procedures, services, and applications and envision possibilities for the trainee's own library/information center. This way, there is more of a sense of participation and involvement.

The success of the internship at Columbia College can be attributed to several factors:

- incorporation of English Language training;

- practical nature of the training program; awareness of working conditions in trainee's home country;

- awareness of professional needs of the trainee;

- a degree of accountability;

- highly customized training schedule to meet specific, realistic objectives;

- content-based framework;

- congenial atmosphere of the training environment;

- close contact with the trainers at both training locations

- opportunity for feedback and modification of the program; and

- follow-up activities headed by the Canadian librarian (project coordinator, information resources component) on a return visit to help implement further developments.

The library staff who participated at different levels benefitted from the contact in different ways. All staff learned about another culture. Daily communications were enlivened. The professional staff who had greater contact with the trainee benefitted most from the exercise. For the trainer and mentor who formulated the training program and coordinated it, a wealth of experience was reaped.

While training one librarian over such a short span of time may seem insignificant in

(continued on page 120) 


\section{2:45 a.m.}

Your day's cataloging is being meticulously scrutinized. obsolete headings are being flipped. Matching authorities records are being added to files. How did you accomplish all this?

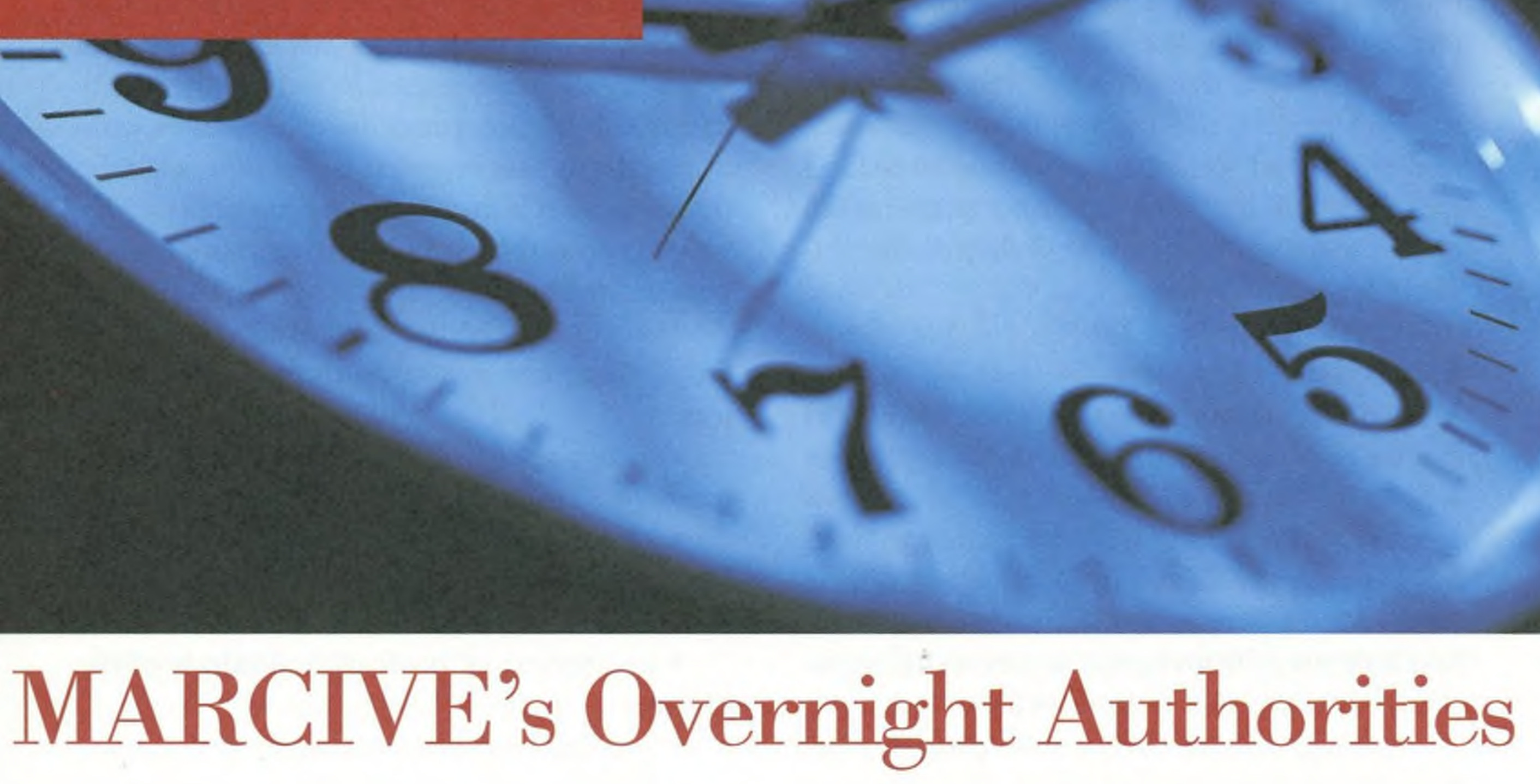

\section{MARCIVE's Overnight Authorities}

With MARCIVE's Overnight Authorities service, your catalogers can have a life - and your

\section{Migrating} from a legacy system?

Contact us today for a competitive quotation for authority work as you migrate. patrons can have access to an OPAC that's always in top form. It's fast, flexible, affordable, and accurate. Best of all, it happens overnight, over the net. When we work the night shift, you have a better catalog in the morning.

price. quality. delivery.

The MARCIVE Value System

\section{Thartive.}

P.O. Box 47508 - San Antonio, TX 78265

Fax 210-646-0167 • www.marcive.com info@marcive.com

\section{$1-800-531-7678$}


sources. Access: http://www.dpa.org.sg/DF/ databases.html.

\section{Electronic journals}

- Deaf Magazine. Compiles articles of interest on deafness and files of information on such topics as cochlear implants. Access: http://WWW.Deaf-Magazine.Org/.

- DeafNation.com (Deaf newspaper). Covers sports, news, classified ads, job mar-

("ACRL/Harvard . . ." continued from page 108)

from sailing to off-site storage to pets to license agreements.

Was it worth it? Yes. In our opening session, Cliff Baden assured us that they "would not waste our time." Time is precious and our time was very well invested. I left with a confidence that came of sharing with a diverse cross-section of academic library directors and upper managers from the United States, Canada, and Puerto Rico.

What did I learn? Foremost, I learned to reframe all major issues: to look at the political, human resource, structural, and symbolic aspects of campus and library issues, and to explore solutions that take all four of these views, or frames, into account. I discovered which frames come naturally and which I need to work on a bit more. I also learned to perceive the leadership of other administrators in my institution using these frames. This helps me in my interactions. I learned about strategic intent and why strategic planning can fall flat, despite the best of facilitators. I learned to laugh and tell stories that get laughs. I learned to take time to think and analyze. I learned to create a secure structure. I learned to pay attention to the context, not just the content. I learned to set standards, have expectations, take risks. Not bad for a five-day institute! ket, maps to events, religion, mailing lists, and telnet sites of interest to people with hearing disabilities. Access: http:// www.deafnation.com/.

\section{Discussion groups}

- Deaf Notes. This is an electronic discussion group on issues of interest to people with hearing disabilities. Access: http://www. deafnotes.com/.

I also learned fascinating things like where Emerson and Thoreau (and Bill Gates, Tommy Lee Jones, and Al Gore) lived as undergraduates. I learned the name of the luminous green grass growing in my garden from the astounding glass flower exhibit at the Harvard Museum of Natural History.

And I learned that it's very hard to eat lobster with plastic flatware! I was able to wander in bookstores. I ate dinner in the Henry James House. I learned about the dominant Harvard finance principle of "each tub on its own bottom."

I met creative librarians, impassioned professors, and some dynamic institute staff whom we all wanted to spirit away to our own campuses. I met undergraduate and graduate students on the streets of Cambridge and in the libraries of Harvard.

I am back, I am energized, and I think I have a new approach.

The 1999 participants are hoping to have a reunion, since the class bonded so well, and we should have success stories to tell in a year or two.

My sincere thanks go to Maureen Sullivan, John Collins, Althea Jenkins, and Cliff Baden who conceived the program and recruited the stellar faculty: Lee Bolman, Robert Keegan, Mary Louise Hatten, and Jim Honan.-Maryruth Phelps Glogowski
("The training . . continued from page 113) the larger scheme of things, it is nonetheless a worthwhile experience. As a result of this internship, one more foreign information center is running better and providing better service than if this training never took place.

Library staff development in this context complements other aspects of the development project of which information service enhancement is an important part. The coor- dinator of the information component reports that visible progress is being made at the information center and the trainee maintains contact via e-mail.

\section{Notes}

1. Nicoletta M. Hary and Francesca L. Hary, "Hosting an International Librarian," College and Research Libraries News (March 1995): 162-164. 